\title{
Analysis of Efficiency of Exploration Type Outgoing Economic Responsibility Audit Internal Audit Factors (CFA) Study
}

\author{
Xing Li \\ ${ }^{1}$ LongDong University, No. 45, LanZhou Rd., XiFeng District, QingYang City 745000, Gansu, China \\ ${ }^{2}$ Department of Business Administration, Asia University, Taichung County 41354, Taiwan \\ Mian Lin \\ Department of Business Administration, Asia University, Taichung County 41354, Taiwan
}

\begin{abstract}
Outgoing efficiency problem of economic responsibility audit of internal audit in the effects of different factors and various specific problems in the actual operation, set up the structural equation model of economic responsibility audit efficiency of outgoing internal audit, and observe the several links improve efficiency choice between each link of observation variables, so as to construct the measurement model, the survey data were analyzed by AMOS software, the path diagram measurement model, found in the focus of the audit, audit system , audit standard feedback mechanism and the professional quality of auditors facing the internal audit of economic responsibility audit efficiency biggest impression, is promoting the improvement priority audit of economic responsibility audit.
\end{abstract}

KEYWORD: Audit; CFA; internal audit; AMOS; efficiency

\section{INTRODUCTION}

Since Chinese government administrative departments, enterprises and institutions to carry out the economic responsibility audit outgoing cadre, the use of administrative means management functions, functional organic ground and business means to supervise the cadres together, so that the cadres of the economic management activities under all under the supervision, to further promote the administrative cadres to the positive role of selfdiscipline, enhance the responsibility consciousness and the risk consciousness, improve the work, management level. At the same time also provides important reference for the party and government departments, the Organization Department cadre choose appoint. But in the actual operation situation of the audit work, outgoing economic audit limitation still exists, the low audit quality and efficiency is lagging behind the larger more prominent.

With government departments attach great importance to the outgoing economic audit, the audit efficiency has attracted a lot of attention. Therefore, the efficiency of auditing structure model of internal audit to construct a multi factor in outgoing economic responsibility audit. Because AMOS software every step in the process of building the model in equation can provide graphical environment, through rapid model to test your variable is how to affect each other and cause this effect. This paper is trying to through the verification of a AMOS model was established by the path diagram to analyze the efficiency of auditing economic responsibility audit office in. Through the analysis of the audit efficiency in the audit, find out the main reason affecting audit efficiency is not high, in order to enhance the internal audit efficiency reference.

\section{DEFINITION OF INTERNAL AUDITING EFFICIENCY}

Internal audit is the independent review and evaluation by this unit interior special audit institutions and personnel of the unit of financial and economic activities, the audit results to this unit primarily responsible for the report. This audit has significant and constructive to the service, the goal is to help this unit perfect internal control, to improve management, enhance economic efficiency. In western countries, the internal audit is generally considered to be the eyes and ears of the manager, assistant and advisor. In 1999, the International Institute of internal auditors (IIA) Council adopted the new definition of internal audit, points out: "internal auditing is an independent, objective assurance and consulting services. Its aim is to add value and improve the operation, through the system, standardize the means to assess the risks, improve risk control and governance, to achieve 
organizational objectives." The audit efficiency (Audit Efficiency) is refers to between the audit cost and audit results and the practice in the audit work of the ratio relationship, is an important index of audit institutions to strengthen internal management, reduce the risk of audit, improve audit quality.

\section{RESEARCH METHODS AND DATA PROCESSING}

\section{1 research methods}

For a long time the audit efficiency problem many scholars have studied the related literature, to improve efficiency and puts forward views and valuable method, but by reading the relevant literature, the research for more quantitative analysis of the lack of audit efficiency, with mathematical analysis to the model of more mature, this paper attempts to prove that through the graph the path AOMS, the outgoing economic responsibility audit, analyzing the influence of audit efficiency of inference, based on the structural equation model (SEM) and the measurement equation model. Structure refers to the relationship between latent variables, and other variables cannot explain the variation model of parts: measurement model describes the dominant indicator of potential variables to be corresponding to the measured or conceptualization. The model contains three variables: the observation variables, latent variables and the error variables. Latent variable has 4: the focus of the audit, audit system, audit and feedback mechanism and the professional quality of auditors. Because these variables are difficult to measure directly, so called latent variables. The observation variables is used to reflect the underlying variables and measured variables, the observation variables selection table 1. Error variable refers to the deviation caused by the observation variables when measuring or caused by minor deviations observed variables.

Table 1. observation variables table.

\begin{tabular}{|l|l|}
\hline Independent variable & Dependent variable \\
\hline Audit Focus & Key data. Reflect the problem of audit. Sector focus. High risk business \\
\hline Standard audit system & Audit pass lead time, Establishment of different audit system, Any of the audit time division \\
\hline Audit and feedback mechanism & $\begin{array}{l}\text { Pay attention to the audit conclusion. Tracking audit } \\
\text { mechanism of internal audit effectively, establishment of audit archives }\end{array}$ \\
\hline Auditors quality & $\begin{array}{l}\text { Service quality. Financial foundation. } \\
\text { internal control system.. Continuing Education }\end{array}$ \\
\hline
\end{tabular}

\subsection{1 structure model}

$\xi$ is independent variable; $\eta$ is Dependent variable; e is Disturbance variables: $\lambda$ Is path coefficient, As shown in figure 1.Figure 1 regression equations between variables as potential:

$\eta=\lambda_{1.1+} \xi_{1}+\lambda_{1.2+} \xi_{2}+\lambda_{1.3+} \xi_{3}+\lambda_{1.4+} \xi_{4}+e$

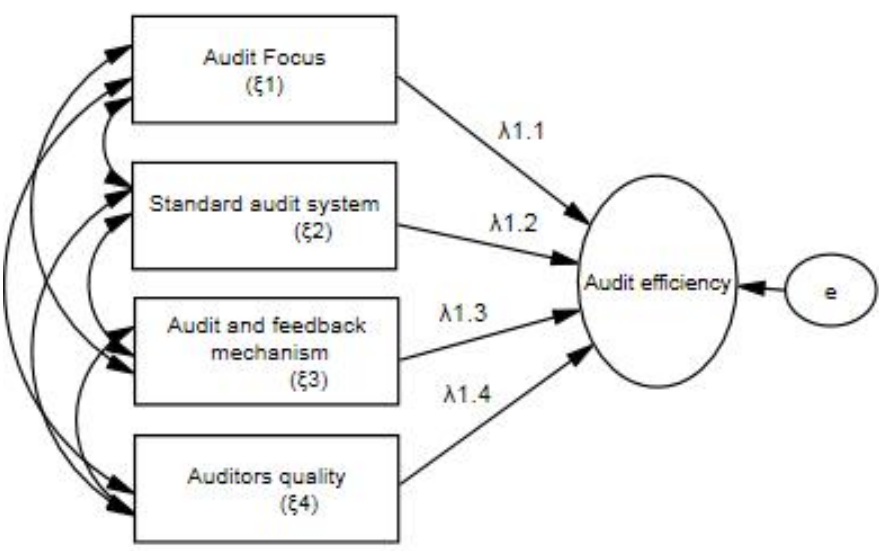

\subsection{2 measurement model}

The outgoing economic responsibility audit the entire audit process as an example to introduce the measurement model, see figure 2 .

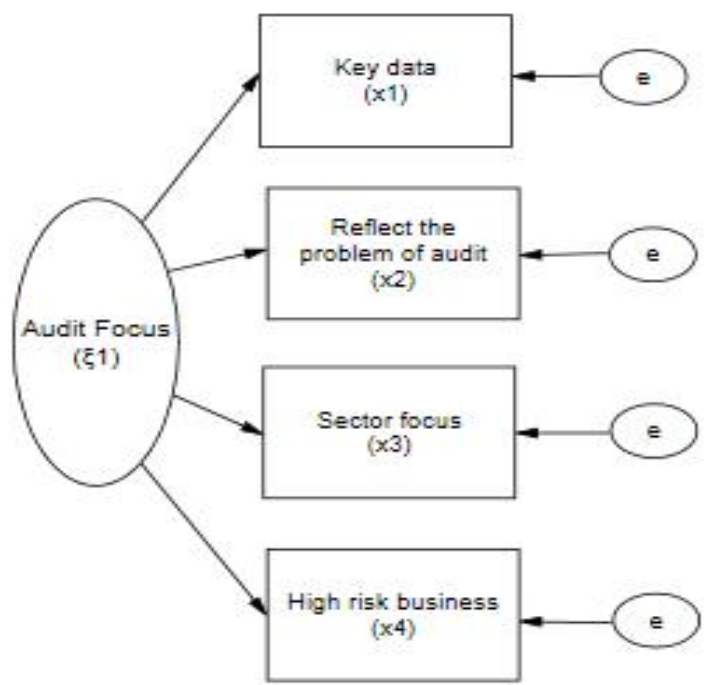

Figure.2

Figure.1 


$$
\begin{aligned}
& x_{1}=\lambda_{1.1+} \xi_{1}+e_{1} \\
& x_{2}=\lambda_{1.2+} \xi_{2}+e_{2} \\
& x_{3}=\lambda_{1.3+} \xi_{3}+e_{3} \\
& x_{4}=\lambda_{1.4+} \xi_{4}+e_{4}
\end{aligned}
$$

The regression equation is expressed as a matrix equation:

$$
X=\Lambda_{X} \xi+\delta
$$

\subsubsection{Estimation method for model}

AMOS Analysis of Moment Structures (abbreviated analysis of moment structure),can verify all kinds of measurement model, different path analysis model; also can be multiple group analysis, the average number of test structures, but the group or multiple group multiple competing models or alternative optimal selection model. With the AMOS into the SPSS family, its use in more and more. Moment structure with covariance matrix content similar, suitable for structural equation modeling (SEM) analysis, this analysis is also called the analysis of covariance structure analysis or causal model.

\section{2 data collection and processing}

The effective questionnaire application enterprise audit workers on an internal economic responsibility audit in the interview questionnaire obtained data analysis. A total of 139 copies of valid questionnaires, including the internal audit staff in 106 copies, 33 copies of the audited object. For the lack of questionnaire in value by using the SPSS software, be filled with the average.

\section{RESULTS AND ANALYSIS}

\subsection{Results}

Calculation by AMOS20.O software, the standardized path model shown in figure3. The observation variables at the top right of figure represents the variance, the external variables of digital two variables of the product moment correlation coefficient, and the single arrow symbol on a number of external variables on the path coefficient of internal variables (standardized regression coefficient).

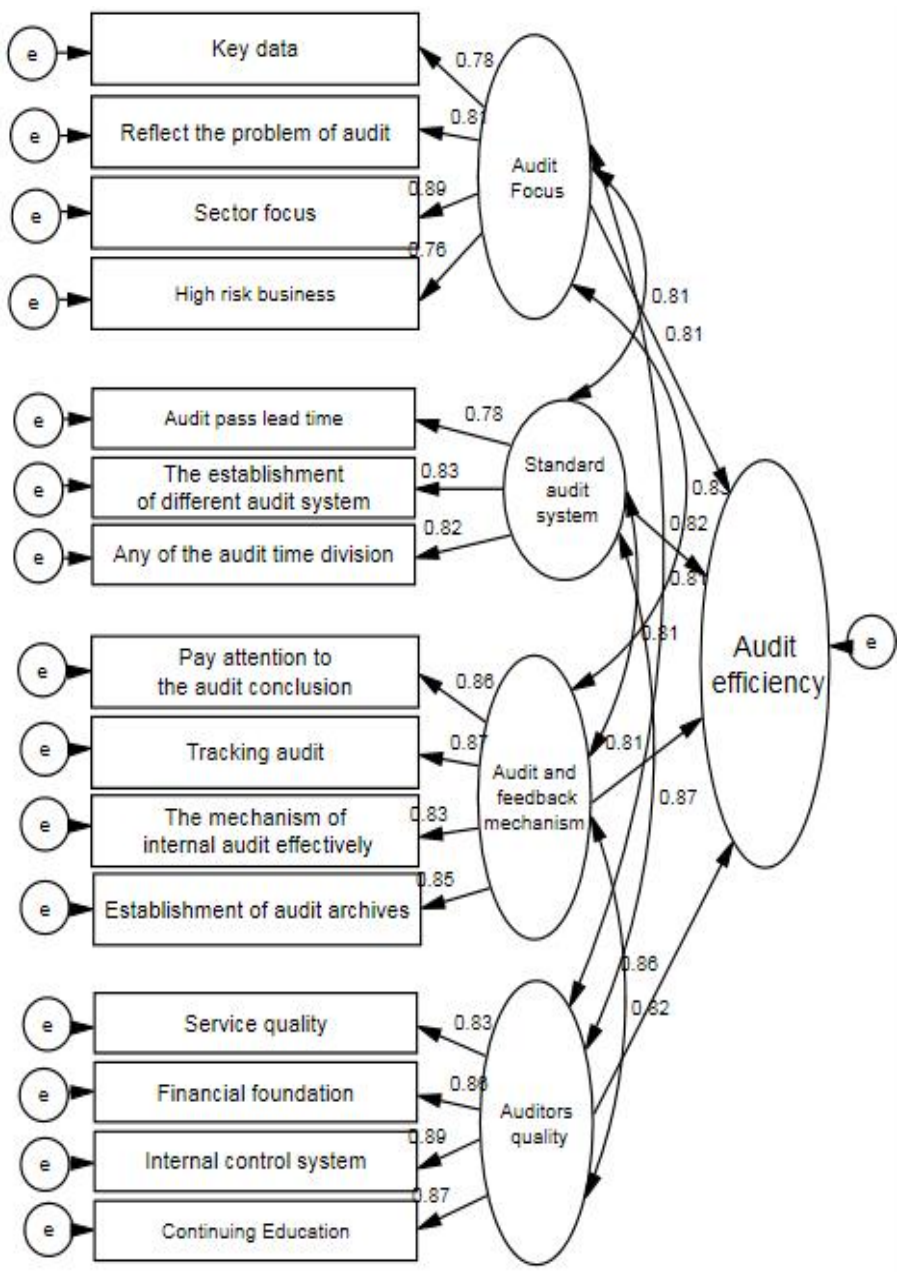

Figure. 3

\subsection{Analysis}

As you can see from Figure 3, the path coefficient four observation variables audit priorities were higher, especially focus on the data delivery path coefficients high, in the audit process can find the key data will affect the efficiency of auditing.

Audit and feedback mechanism system link, pay attention to the audit conclusion path coefficient tracking audit system audit effectively establish audit records of three observed variables are relatively high, especially tracking audit to improve the efficiency of the highest, internal audit, several aspects of this work should be improved.

The quality of audit personnel department links, Business Internal Control System Based on the quality of the financial path coefficients of four variables is relatively higher education. The internal audit work to improve the overall efficiency, staff quality raise to help improve the efficiency of.

The four service links of internal audit, audit, audit and feedback path coefficient on fitness and quality of audit staff of the three was significantly higher than that of economic responsibility audit is the standard audit system, the first should be the focus of ascension focus of the audit, audit and feedback physique and auditors quality three aspects of the service ability. 


\section{CONCLUSION}

To sum up, the internal economic responsibility audit to improve audit efficiency,due to start from the focus of the audit, audit system, audit and feedback mechanism and the professional quality of auditors four.

\section{REFERENCES}

[1] H. Ashbaugh, R. Lafond, B.W. Mayhew, Do non-audit services compromise auditor independence? Further evidence, Accounting Review, 78 (2003), pp. 611-639

[2] M. Barclay, R.H. Litzenberger, Announcement effects of new equity issues and the use of intraday price data, Journal of Financial Economics, 21 (1988), pp. 71-99

[3] Lixing, 'How to improve the Quality and Efficiency of Economic Audit on University leaders leaving', Journal of Longdong University,1,(2013),pp.99-101

[4] V.L. Bernard, Cross-sectional dependence and problems in inference in market-based accounting research, Journal of Accounting Research, 25 (1987), pp. 1-48

[5] P.K. Chaney, K.L. Philipich, Shredded reputation: the cost of audit failure, Journal of Accounting Research, 40 (2002), pp. 1221-1245
[6] C. Chow, The demand for external auditing: Size, debt, and ownership influences, The Accounting Review, 57 (1982), pp. 272-291

[7] L. DeAngelo, Auditor size and audit quality, Journal of Accounting and Economics, 3 (1981), pp. 183-200

[8] R. Dye, Auditing standards, legal liabilities, and auditor wealth, Journal of Political Economy, 101 (1993), pp. 887-914

[9] M. Jensen, The modern industrial revolution, exit, and the failure of internal control systems, Journal of Finance, 48 (1993), pp. 831-880

[10] Kinney,W, Z. Palmrose, S. Scholz, Auditor independence, non-audit services, and restatements: Was the US government right?, Journal of Accounting Research, 42 (2004), pp. 561-588

[11] Shu.S, Auditor resignations: clientele effects and legal liability, Journal of Accounting and Economics, 29 (2000), pp. 173-205

[12] Krishnan,J (Krishnan, J),Audit committee quality and internal control: An empirical analysis,80.2(2004),pp.649675

[13] Neter, J; Kutner, MH; Nachtsheim, CJ; Wasserman, W. Applied linear statistical models : 1996

[14]Dechow, PM; Dichev, The quality of accruals and earnings: The role of accrual estimation errors, IDACCOUNTING REVIEW, 77, S, 2002, pp. 35-59 